\title{
IDENTIFYING RISK FACTORS FOR INCAUTIOUS USE OF NON-PRESCRIPTION DRUGS AMONG HIGHER EDUCATION INSTITUTIONS' STUDENTS IN EMIRATES
}

\author{
KHALID AWAD AL-KUBAISI ${ }^{1}$, MARK DE STECROIX ${ }^{1}$, DON VINSON ${ }^{2}$, ABDUELMULA RAJAB ABDUELKAREM ${ }^{3 *}$ \\ ${ }^{1}$ Department of Paediatric Sport and Exercise, University of Gloucestershire, The Park, Cheltenham, England. ${ }^{2}$ Department of Sport and \\ Exercise Science, University of Worcester, St John's Campus, Henwick Grove, Worcester, WR2 6AJ, United Kingdom. ${ }^{3}$ Department of Clinical \\ Pharmacy and Pharmacy Practice, University of Sharjah, Sharjah, UAE. Email: aabdelkarim@Sharjah.ac.ae
}

Received: 25 January 2017, Revised and Accepted: 04 July 2017

ABSTRACT

Objective: The aim of this research is to identify risk factors for incautious use of oral non-prescription drugs (ONPD) and inform recommendations that promote cautious ONPD use among HEI students in the UAE.

Methods: A cross-sectional survey-based study was conducted with 2875 students in three randomly selected UAE universities between January and April 2014.

Results: More than half $(1348 ; 57 \%)$ of participants reported using of ONPD in the past 90 days before study commencement. Of 1348 participants reported using ONPD, one-quarter (1348; 22.2\%) of ONPD was classified as incautious ONPD usage. Analgesic/antipyretic (84.9\%), non-steroidal anti-inflammatory drugs (NSAIDs) (1028; 76.3\%), and cough and cold drugs (562; 41.7\%) were reported by the majority of participants as the most commonly used ONPD. 10 risk factors were identified for incautious ONPD use. Participants with age group of 21 years and older (OR=0.554, 95\%; $\mathrm{CI}=0.373-0.823 ; \mathrm{p}<0.001)$, female $(\mathrm{OR}=0.339,95 \%$; $\mathrm{CI}=0.236-0.486 ; \mathrm{p}<0.001)$, and students from medical schools $(\mathrm{OR}=0.619,95 \%$; $\mathrm{CI}=0.435-0.882$; $\mathrm{p}=0.008$ ) had lower odds of being incautious users compared to lower age group, males, and students from non-medical schools. Furthermore, participants with a polypharmacy behavior had higher odds of being irresponsible ONPD user than monopharmacy users $(0 R=1.400,95 \%$; CI=1.030$1.02 ; \mathrm{p}<0.001)$.

Conclusion: One of five students is an incautious ONPD user. There is a need for an educational and behavioral intervention to motivate students to be cautious users.

Keywords: Oral non-prescription drugs, Higher education institution, Cautious drug use, Risk factors, UAE.

(C) 2017 The Authors. Published by Innovare Academic Sciences Pvt Ltd. This is an open access article under the CC BY license (http://creativecommons. org/licenses/by/4. 0/) DOI: http://dx.doi.org/10.22159/ajpcr.2017.v10i10.17290

\section{INTRODUCTION}

A patient package insert or drug information leaflet contains information for consumer about how to use their drugs safely and effectively, and it is part of the FDA-approved drug fact labeling [1]. Furthermore, drug facts label is a printed label on the box of drugs, containing important information about the safe use of the drug, such as active ingredients, uses, warnings, directions of use, inactive ingredients, and other information, and it is a part of drug information leaflet.

For safe and effective use of non-prescription drugs, it is important to read and understand the non-prescription drugs informational insert leaflet/ label [2,3]. In the USA, Ellen and other researchers [4,5] studied 295 undergraduate university students and found that, over the counter drugs (OTC), drugs overdose is largely unintentional because the consumer is not reading and understanding the informational drug leaflet.

A regional study aimed at analyzing responsible self-medication practice with non-prescription drugs, Bolañosinter viewed 5251 of nonprescription drugs consumers, aged 18 years and older, in pharmacies across eight different countries in Latin America comprising of Argentina, Brazil, Colombia, Costa Rica, El Salvador, Guatemala, Mexico, and Vnezuela [2]. The study was conducted throughout four seasons from April 2002 to May 2003 to provide accurate and reliable information among northern, central, and southern regions of Latin America. The researcher concluded that the consumers are responsible and cautious users if they read the drug label before use for the first time. Accordingly, to differentiate between different terms that describe the categories of ONPD users, the present study is operationally defined cautious ONPD user as a user who reads the ONPD information leaflet before using the ONPD for the first time.

No study to date has explored incautious ONPD use among UAE Higher Education Institution students. The present study aims at measuring the prevalence of ONPD use, assessing the incautious use, and identifying risk factors associated with incautious ONPD use among university students in UAE.

\section{METHODS}

The present study was conducted after the approval of the Institutional Ethics Committee in UAE and Gloucestershire University, UK. Before participation in the study, all potential participants were informed of the aim of the study and were informed of their right to refuse participation or withdraw from the study at any point without prejudice before completing the survey. Students were informed that, by completing the questionnaire, they do agree to participate in the study.

The study employed a cross-sectional, analytical design to achieve its objective. Sample size was calculated based on the method to estimate a proportion with specified precision [5]. The true value for the proportion of inappropriate use of ONPD was assumed $50 \%$, which maximize the needed sample size. The desired level of confidence is set at $5 \%$, and the desired level of precision equals 0.03 on either side, i.e., the estimated proportion of inappropriate use is within $3 \%$ points of the true value $(47-53 \%)$. 
$\mathrm{n}=(\mathrm{Z} 2 \times \mathrm{P}(1-\mathrm{P})) / \mathrm{e} 2$; where $\mathrm{Z}=$ value from standard normal distribution corresponding to desired confidence level $(\mathrm{Z}=1.96$ for $95 \%$; $\mathrm{CI}$ ); $\mathrm{P}$ is expected true proportion; e is desired precision (half-desired CI width).

A sample size of at least 1068 ONPD users is needed. As the prevalence of ONPD use was reported to be $37.7 \%$ among which is done in Arabian country and shows low prevalence which maximize the needed sample size as well [6-8]. To be able to get 106 ONPD users, a total number of 2833 students was required. The study collected 2875 responses which turned out to include 1348 ONPD users during the past 90 days before contacting each subject to reduce recall bias.

A multistage sampling technique was been used in the present study through using a three-step cluster sample method [7]. In steps 1 and 2, three universities (out of five UAE HEI that offer medical and non-medical programs) were randomly selected. In the second stage, three medical and non-medical colleges from each university were selected by stratifying on medical and non-medical colleges, and then, a simple random sampling technique was used to select one college from medical and two colleges from non-medical colleges within each university. In step 3, random sample from each year of study at the selected colleges was chosen using simple random table.

To measure the internal consistency reliability of the questionnaire, reliability analysis was used and Cronbach's Alpha $(\alpha)$ was calculated for the pilot study ( $n=20$ for phase two) after the questionnaire was adjusted based on feedback from phase one $(n=80)$. The modified questionnaire has excellent reliability, Cronbach's $\alpha$ was 0.931, indicating that most of the items included make a valid contribution to the overall score.

The assessment of irresponsible use was adopted and modified from an existing published instrument [9]. Participants were asked whether they read the ONPD leaflet before first use and choose between four responses: Always, often, rarely, or never. Participants were considered as cautious ONPD users if reported that they always or often read the ONPD information leaflet at the first time of use, while participants who reported that they rarely or never read the ONPD information leaflet at the first time of use were considered to be incautious ONPD users. Cautious ONPD use was scored as a binary variable: Always or often read $=1$ and rarely or never read $=0$.

The present study adopted Anderson's behavioral model for factors of health-care utilization which sort risk factors of irresponsible ONPD use into predisposing factors, enabling factors, and need factors [10]. Potential risk factors of irresponsible use were grouped into (1) predisposing factors, such as four demographic characteristics and nine health belief characteristics, (2) enabling factors such as colleges, year of study, OTC-knowledge, medication knowledge, professional, informal, radio and television, newspaper/magazines, reading the medical books and the internet, and previous experience source of ONPD information, and (3) need factors such as save money, save time, minor illness, prevention of disease, previous experience, emergency of use, and ONPD are just as effective as prescription drugs, self-care orientation, and perceived-health reasons for ONPD.

Binary logistic regression (BLR) was used to identify factors associated with incautious ONPD use. For this analysis, the dependent variable was coded as cautious ONPD use $=0$ and incautious ONPD use $=1$. The independent variables included the 32 variables (predisposing variables, enabling variables, and need factors) that are potentially risk factors/predicators of incautious ONPD use. Predictor variables were statistically significant at $\mathrm{p}<0.05$.

\section{RESULTS}

A total of 2875 questionnaires were distributed over the study period of 3 months. Only 2355 surveys were returned completed and included in the study, giving a response rate of $81 \%$. Out of those who accepted to participate, more than half $(1348$ of $2355 ; 57.2 \%)$ of the participated students reported using ONPD in the past 90 days before conducting the study and were asked to complete the survey. Of those ONPD users, almost one-quarter $(299 ; 22.2 \%)$ reported that they have either never or rarely read the drug information leaflets before the first time of drug's use and classified as incautious ONPD users. Among the 2355 students participated in this study, the majority was females $(1797 ; 76.3 \%)$, single $(2151 ; 91.3 \%)$, and not employed during the study period (2190; $93 \%)$. Almost three-quarter $(1417 ; 60.2 \%)$ of the sample pooled was between the age of 19-21 years. Details about participant's personal information are presented in Table 1.

Analgesic/antipyretic (1144; 84.9\%), NSAIDs (1028; 76.3\%), and to cough and cold related drugs $(562 ; 41.7 \%)$ were reported by the majority of 1348 participants under investigation as the most commonly used ONPD. Fig. 1 shows the types of the commonly used ONPD medication over the study period. More than three-quarter $(1061 ; 78.7 \%)$ and more than half $(734 ; 54.4 \%)$ of respondents reported that the main reason for using of ONPD was management of minor illness and saving time, respectively. The frequency and percentage of the most common reason for self-treatment with ONPD are summarized in Table 2.

BLR was conducted to identify risk factors of the incautious use of ONPD and to estimate the individual probability of incautious use of

Table 1: Demographic characteristics of the participants $(n=2355)$

\begin{tabular}{|c|c|}
\hline Demographics & n (\%) \\
\hline \multicolumn{2}{|l|}{ Age } \\
\hline 18 & $161(6.8)$ \\
\hline $19-21$ & $1417(60.2)$ \\
\hline $22-24$ & $683(29)$ \\
\hline $25-27$ & $75(3.2)$ \\
\hline $28-30$ & $7(0.3)$ \\
\hline Above 30 & $12(0.5)$ \\
\hline \multicolumn{2}{|l|}{ Gender } \\
\hline Female & $1797(76)$ \\
\hline Male & $558(24)$ \\
\hline \multicolumn{2}{|l|}{ Marital status } \\
\hline Single & 2151 (91.3) \\
\hline Married & $186(7.9)$ \\
\hline Divorced & $11(0.5)$ \\
\hline Others & $7(0.3)$ \\
\hline \multicolumn{2}{|l|}{ Ethnicity } \\
\hline UAE National & $1073(45.6)$ \\
\hline Arab & $1068(45.4)$ \\
\hline Asian & $86(3.7)$ \\
\hline Iranian & $88(3.7)$ \\
\hline Others & $40(1.7)$ \\
\hline \multicolumn{2}{|l|}{ Universities } \\
\hline Sharjah University & $681(28.9)$ \\
\hline UAE University & $837(35.5)$ \\
\hline Ajman University & $837(35.5)$ \\
\hline \multicolumn{2}{|l|}{ Year of study } \\
\hline 1 & $175(7.4)$ \\
\hline 2 & $560(23.8)$ \\
\hline 3 & $713(30.3)$ \\
\hline 4 & $670(28.5)$ \\
\hline 5 & $190(8.1)$ \\
\hline 6 & 472 \\
\hline \multicolumn{2}{|l|}{ Income level } \\
\hline Below 10,000 & $170(7.2)$ \\
\hline $10,000-20,000$ & $506(21.5)$ \\
\hline $20,000-50,000$ & $581(24.7)$ \\
\hline Above 50,000 & $221(9.4)$ \\
\hline Do not know & $877(37.2)$ \\
\hline \multicolumn{2}{|l|}{ Employment status } \\
\hline Yes & $165(7)$ \\
\hline No & $2190(93)$ \\
\hline Total & $2355(100)$ \\
\hline
\end{tabular}


Table 2: The distribution of most common reasons for self-treatment with ONPD $(n=1348)$

\begin{tabular}{ll}
\hline Reason (s) for ONPD use & n (\%) \\
\hline Minor illness & $1061(78.7)$ \\
Saving time & $734(54.5)$ \\
Previous experience & $572(42.4)$ \\
Emergency & $330(24.5)$ \\
Disease prevention & $182(13.5)$ \\
Saving money & $177(13.1)$ \\
As effective as prescription drugs & $62(4.6)$ \\
\hline
\end{tabular}

ONPD: Oral non-prescription drugs

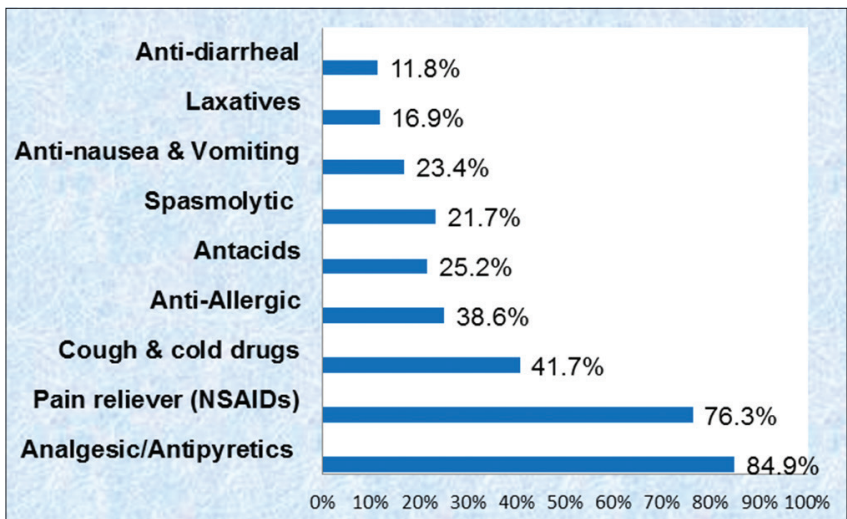

Fig. 1: Types of the commonly used oral non-prescription drugs categories $(n=1348)$

ONPD. The Hosmer and Lemeshow goodness of fit test was statistically non-significant $(\mathrm{p}=0.898)$, indicating a good model fit of the data. The statistically significant $(p<0.001)$ Cox and Snell R2 (0.147) and Nagelkerke R2 (0.225) suggest a modest power of prediction. The combination of 32 predictor variables resulted in $80.1 \%$ correct classification of cautious and incautious ONPD user. In this model, ten explanatory variables were identified as statistically significant risk factors of incautious ONPD use. The risk factors of incautious ONPD use included age, gender, polypharmacy, trust in health-care professional, medical advice seeking behavior, professional-source of ONPD information, informal source of ONPD information, reading medical books and the internet, being a non-medical medical student, and selfcare orientation.

Participants with age group of 21 years and older $(\mathrm{OR}=0.554$, 95\%; CI=0.373-0.823; $\mathrm{p}<0.001)$, females' participants $(\mathrm{OR}=0.339$, $95 \%$; $\mathrm{CI}=0.236-0.0486 ; \mathrm{p}<0.001)$, and students from the medical schools (OR=0.619, 95\%; $\mathrm{CI}=0.435-0.882 ; \mathrm{p}=0.008)$ have lower odds of being incautious ONPD user compared to those with lower age group, male, and non-medical students respondents. Furthermore, participants with high self-care attitudes have a significant lower odd of being incautious ONPD (OR=0.673, 95\%; CI=0.495-0.916; $\mathrm{p}=0.012$ ). Participants using more than one drugs for treating a single illness (polypharmacy) have higher odds of being incautious ONPD user compared to monopharmacy users $(\mathrm{OR}=1.400,95 \%$; $\mathrm{CI}=1.030-1.02 ; \mathrm{p}<0.001)$. In addition, participants who did not seek any medical advice from the pharmacist have higher odds $(\mathrm{OR}=2.454,95 \% ; \mathrm{CI}=1.787-3.368 ; \mathrm{p}<0.001)$. Interestingly, ONPD users who reported the usage of information from informal sources have significantly higher odds of being incautious users compared to those users who not use any informal sources $(\mathrm{OR}=1.544$, 95\%; $\mathrm{CI}=1.138-2.094 ; \mathrm{p}=0.005$ ). Failure to use ONPD information from reading medical books or the internet was associated with a significant high odds of being incautious ONPD users (OR=1.968, 95\%; $\mathrm{CI}=1.389-2.789$; $\mathrm{p}<0.001$ ). The 1348 participant's proportion of cautious an incautious use of ONPD by risk factors is summarized in Table 3.

\section{DISCUSSION}

Medication is important for prompting human health and maintaining well-being of our nation, and it is obvious to outweigh the risks of benefits and rational use of drugs [11]. This is more important in health-care system with easy availability of the drugs, inadequate health service, and lack of regulatory control on drug self-medications. The prevalence of incautious ONPD usage (22.2\%) although minimal, many of the students at the university levels were not aware of the ONPD effects on their health and the need for awareness campaigns targeting incautious students is high. However, the minimal percentage presented here might be attributed to the fact that the present study only included university students, who may have high awareness about the importance of reading drug information leaflets before ONPD use. This finding is consistent with the previous studies among university students, where reading the drug package insert before use ranged from $72 \%$ to $94 \%$ among medical students in Bahrain [12,13]. To improve such findings to almost $100 \%$, pharmaceutical companies need to develop drug information leaflets that are more attractive to university students, such as changing the font size to increase readability [14].

Participants with an age group of 21 years and older (OR=0.554, 95\%; $\mathrm{CI}=0.373-0.823 ; \mathrm{p}<0.001)$ and females $(\mathrm{OR}=0.339,95 \%$; $\mathrm{CI}=0.236$ 0.0486 ; $p<0.001$ ) had lower probability of being incautious ONPD user compare to those with a lower age group and male. These findings are different from the results of other study related to age group [15] and in consistent with the study related to females were more likely to seek health information than males $[12,16]$. One can contemplate that higher age group users and females have more responsibilities and being wiser to be conscious regarding the importance of reading the drug information leaflets for enhancing safe and effective use of drugs. Polypharmacy behavior (using more than one drugs for treating a single illness) had a higher probability of being incautious ONPD user than monopharmacy users. Using more than one drug in self-medication practice for treating a single symptom a day, increasing the likelihood of not reading the drug information leaflets.

Students under investigation were not interesting in the advice provided by pharmacist and such attitude was associated with higher probability of being incautious user of ONPD. This might be attributed to the fact that students included in the study had previous experience or they believe in their knowledge about the use of medication since they are students at the university level. This finding is consistent with other findings in India, where the majority of professional students were not even aware of the dose of drug, active constituents, indications, and side effects of commonly used drugs in self-medication such as paracetamol [17]. This false sense of confidence has to be studied more and should be corrected. Those who did not have a good level of trust in the information offered by health-care professionals were more likely to seek information about the use of ONPDs from drug information leaflets, and consequently, more likely to be cautious ONPD users. Obviously, the relationship between the health-seeking behavior, information-seeking behavior, and better lines of communications on drug use should be established between doctors, pharmacists, and patients [17]. It has been demonstrated in one particular study that participants may intentionally avoid seeking information from healthcare professionals, reading medical books, searching the internet, or from reading drug information leaflets because these sources of information simply "scared" them, for example, by telling them about potential side and adverse effects of a drug $[17,18]$. Considering the fact that family, friends, and neighbors are limited source of information about ONPDs, still, many people believe in their opinion regarding the safe use of drugs $[18,19]$. Health-care providers have to work more to change such behavior in our community.

Medical students had a lower probability of being incautious users compared to non-medical students. This result indicates that medical students have higher awareness about the importance of reading the drug information leaflets before the first time of use compared to non- 
Table 3: The proportions of cautious and incautious ONPD users by risk factors (explanatory variables/predictors) (n=1348)

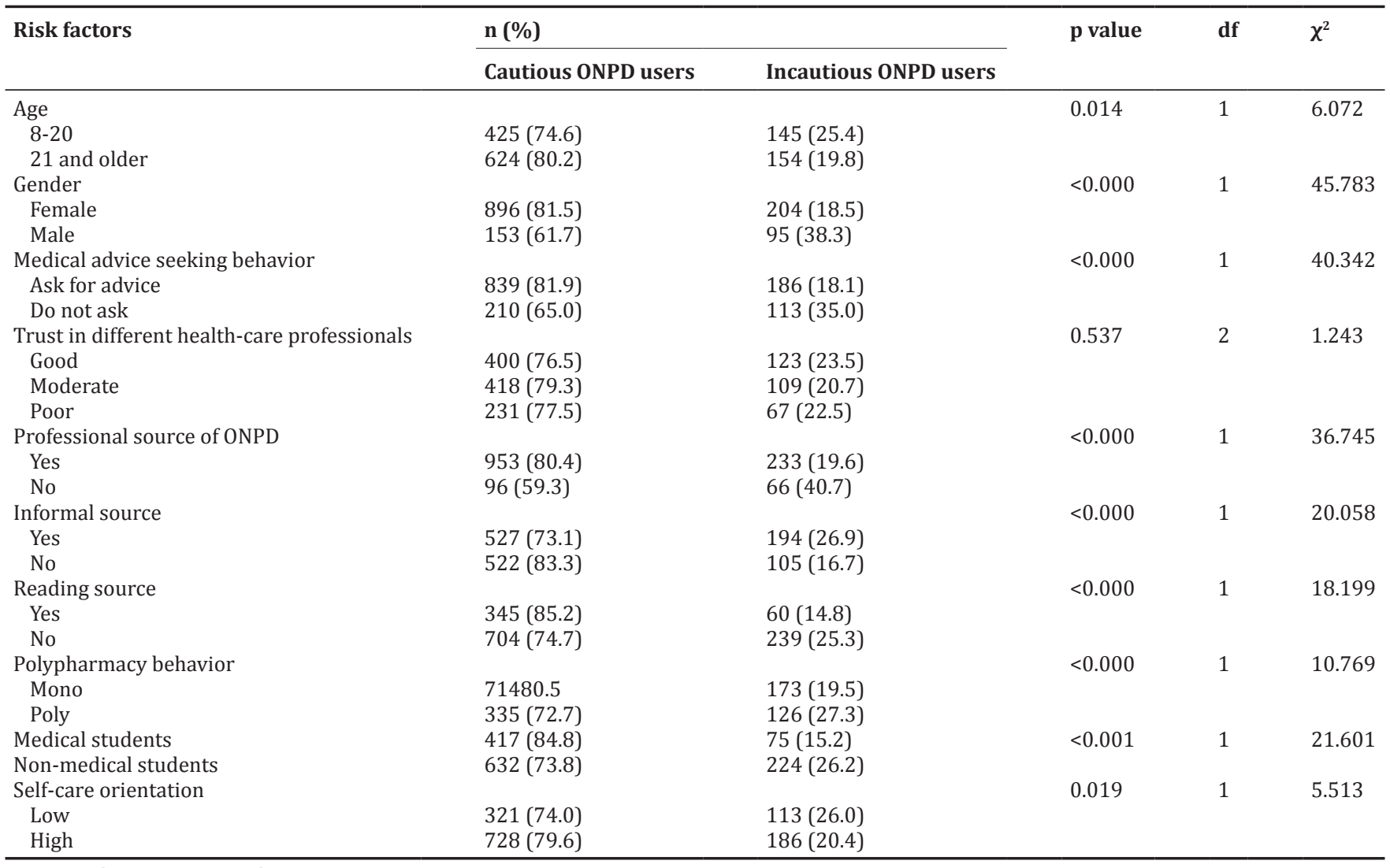

ONPD: Oral non-prescription drugs

medical students. This positive finding is encouraging since medical students might have a false sense of confidence because of having pharmacology courses in their academic curriculum, so they might not eager to read the drug leaflets. Our finding is in agreement with a study in Pakistan - reported a positive attitude of medical and dental studies about the importance of reporting adverse drug reactions related to drug use [20].

\section{CONCLUSION}

The predictive power of the model was modest (Nagelkerke $\mathrm{R}^{2}=0.225$, $\mathrm{p}=0.898$ ), indicating that the reasons behind incautious ONPD use extend beyond the risk factors identified. Further studies are required to investigate additional explanatory variables. One of five students is incautious ONPD user. There is a need for an educational and behavioral intervention to motivate students to be cautious users.

\section{ACKNOWLEDGMENTS}

The researcher would like to thank all participated universities and their students for cooperation and participation in this research study.

\section{REFERENCES}

1. Food and Drug Administration (FDA). Drugs@ Instructions: Health Information. Available from: http://www.fda.gov/drugs/ informationondrugs/ucm079450.htm. [Last accessed on 2016 Nov 15].

2. Bolaños H. Responsible self-medication in Latin America. Drug Inf J 2005;39(1):99-107.

3. Food Drug Administration (FDA). OTC Drug Facts Label. Available from: http://www.fda.gov/drugs/resourcesforyou/consumers/ucm 143551.htm. [Last accessed on 2016 Dec 19].

4. Ellen PS, Bone PF, Stuart EW. How well do young people follow the label? An investigation of four classes of over-the-counter drugs. J Public Policy 1998;17(1):70-85.
5. Daniel WW. Biostatistics: A Foundation for Analysis in the Health Sciences. $7^{\text {th }}$ ed. New York: R Wiley; 1999.

6. Sawalha AF. A descriptive study of self-medication practices among Palestinian medical and nonmedical university students. Res Social Adm Pharm 2008;4(2):164-72.

7. Ross K. Sample Design for Educational Survey Research. France: UNESCO International Institute for Educational Planning; 2005. Available from: http://www.unesco.org/iiep/PDF/TR_Mods/Qu_Mod3. pdf. [Last accessed on 2016 Oct 20].

8. George D, Mallery P. Reliability analysis. SPSS for Windows, Step by Step: A Simple Guide and Reference. $14^{\text {th }}$ ed. Boston: Allyn \& Bacon; 2003. p. 222-32.

9. Lo YN. Consumers'Expectations of Over the Counter (OTC) Medicines: Location of Sale (Doctoral Dissertation, University of Saskatchewan Saskatoon). Available from: http://www.collectionscanada.gc.ca/obj/ s4/f2/dsk3/SSU/TC-SSU-08292006153200.pdf. [Last accessed on 2016 Sep 25].

10. Andersen R. A Behavioral Model of Families' Use of Health Services. Vol. 25. Center for Health Administration Studies Research Series; 1968. p. 111. Available from: https://www.cabdirect.org/cabdirect/ abstract/19702701913. [Last accessed on 2016 Aug 11].

11. Awad A, Eltayeb I, Matowe L, Thalib L. Self-medication with antibiotics and anti-malarials in the community of Khartoum State, Sudan. J Pharm Pharm Sci 2005;8(2):326-31.

12. James H, Handu SS, Al Khaja KA, Otoom S, Sequeira RP. Evaluation of the knowledge, attitude and practice of self-medication among firstyear medical students. Med Princ Pract 2006;15(4):270-5

13. James H, Handu SS, Khaja KA, Sequeira RP. Influence of medical training on self-medication by students. Int J Clin Pharmacol Ther 2008;46(1):23-9.

14. Fuchs J, Heyer T, Langenhan D, Hippius M. New font size requirements in package inserts of medicines. Pharm Ind 2010;72(12):2032-6.

15. Vinker S, Eliyahu V, Yaphe J. The effect of drug information leaflets on patient behavior. Isr Med Assoc J 2007;9(5):383-6.

16. Akici A, Basaran NF. University students' attitudes concerning OTC drug use; Survey from Istanbul. ARPN J Sci Technol 2013;3(3):309-15.

17. Verma RK, Mohan L, Pandey M. Evaluation of self-medication among 
professional students in North India: Proper statutory drug control must be implemented. Evaluation 2010;3(1):60-4.

18. Case DO. Looking for Information: A Survey of Research on Information Seeking, Needs and Behavior. Emerald Group Publishing; 2012. Available from: https://www.books.google.ae/books/about/ Looking_for_Information.html?id=XYX_RV7Wy9QC\&redir_esc=y.
19. Cusack L, de Crespigny C, Wilson C. Over-the-counter analgesic use by urban Aboriginal people in South Australia. Health Soc Care Community 2013;21(4):373-80.

20. Iffat WA, Shakeel SA, Naseem SA, Imam SH, Khan MA. Attitudinal survey to assess medical and dental students' belief of ADR reporting in Pakistan. Int J Pharm Pharm Sci 2014;6(5):279-83. 